\title{
An Explorative Study to Assess the Prevalence of Social Anxiety Disorder (SAD) and Its Determinants among High School Students of Selected High School of Bagalkot
}

\author{
Nagarjun Mundinamani*, Renukaraj Nagammanavar**, Deelip S Natekar ${ }^{* * *}$, \\ Utalbasha N Dandaragi*****
}

\begin{abstract}
${ }^{*}$ MSc. Nursing 2nd Year, Shri B.V.V.S Sajjalashree Institute of Nursing Sciences, Bagalkot, Karnataka.
${ }^{* *}$ Associate Professor, Community Health Nursing, Shri B.V.V.S Sajjalashree Institute of Nursing Sciences Navanagar Bagalkot, Karnataka, India.

${ }^{* * *}$ Principal, (Ph.D in Nursing), Shri B.V.V.S, Sajjalashree Institute of Nursing Sciences, Navanagar, Bagalkot, Karnataka.

${ }^{* * * *}$ Professor, (Ph.D in Nursing), Community Health Nursing Shri B.V.V.S, Sajjalashree Institute of Nursing Sciences, Navanagar, Bagalkot, Karnataka.
\end{abstract}

Corresponding Author: Renukaraj Nagammanavar

DOI: https://doi.org/10.52403/ijhsr.20220117

\begin{abstract}
Introduction: As per research studies have shown that social anxiety disorder has a worldwide prevalence of 5 to $10 \%$ and a lifetime prevalence rate of $8.4 \%$ to $15 \%$ among high school students. ${ }^{1}$ Rural Indian children are facing this problem of lethal evil more as compared to Urban high school students in India.

Objective: To assess the prevalence of social anxiety disorder [sad] and its determinants among high school students of selected high school of Bagalkot.

Methods: Descriptive survey approach was used for the study with cross sectional survey design. 120 high school students between 14 years to 16 years of age were selected Disproportionate stratified random sampling technique method from high school students studying in selected high school of Bagalkot. The data regarding determinants was collected by structured interview schedule and selfreport method. The Social Phobia Inventory (abbreviated as SPIN) is a five point scale was used to categories the high school students according to their social anxiety disorders. The association was explored by Chi square test, Fisher's exact probability test and linear regression.

Results: Total 120 high school students were responded for Social Phobia Inventory (SPIN) scale, in that level of social anxiety disorders had reveals that majority $83.3 \%$ had non phobic, $15.8 \%$ had mild and $0.8 \%$ had moderate, there is no extremely phobic. A significant association was found between the social anxiety disorders of adolescents and their selected socio-demographic variables like monthly income $\left(\chi^{2}=21.199 ; \mathrm{P}<0.05\right)$.

Conclusion: The findings revealed that there was a positive correlation found between the psychological wellbeing and academic performance among adolescents, recommended health education, early recommended understanding the social anxiety disorder and its determinants by their students especially among the fresher`s. Effectiveness of teaching programmes regarding impact of its determinants on level of social anxiety disorders among adolescents can be done had positive effect on adolescents health, which were also statistically significant.
\end{abstract}

Key Words: Social anxiety disorder, Determinants, Adolescents, high school students, academic performance, Spin scale. 


\section{INTRODUCTION}

If children have been feeling this way for at least six months or more and these feelings make it hard for you to do everyday tasks such as speaking to people at work or school you may suffering with social anxiety disorder. Social anxiety disorder [also called social phobia] is a mental illness condition. It is an intense, persistent fear of being watched and judged by others. These fears can affect on behavior or daily activities. It's also hard to keep friends. But social anxiety disorder doesn't have to prevent by reaching your potential. Treatment can help you to your symptoms. ${ }^{1}$

Social phobia is a fear of being judged by someone and of being shy or anxious. This fear can be so strong that it gets in the way to work or schooling or doing other daily activities. People with social phobia are afraid of doing simple things in front of someone; for Ex, they might be afraid to sign a check in front of a cashier at the shops, or they might be embraced to eat or drink in front of people. All of us have been a little bit fear, at one time or another, about things like meeting someone or giving a speech. But children with social phobia worry about these and other things for before few days they happen. Most of the people who have social anxiety disorder know that they shouldn't be as afraid as they are, but they unable to control their fear. Sometimes, they will end up stay away from places or events where they think they want to do something that will embarrass them. That they can keep them from doing the everyday tasks of living and from enjoying times with family and peer groups. ${ }^{2}$

Social anxiety disorder is characterized by persistent fear of being humiliated or scrutinized by somebody (WHO 1992 American Psychiatric Association 2013). Individuals fear a level of social interactions, such as conversations with strangers, joining in groups and speaking on the telephone. Things that involve being observed by others are difficult. Common signs include the fear of sweating, blushing, shaking, sweating, stumbling over words, looking anxious, or appearing boring, stupid, and incompetent (Stein and Stein 2018).

Objective: The aim of the study was to assess the prevalence of social anxiety disorder [sad] and its determinants among high school students of selected high school of Bagalkot.

\section{Hypotheses:}

$\mathrm{H}_{1}$ : There is significant association between social anxiety disorder and selected determinants of high school students.

\section{MATERIALS AND METHODS}

Study design. It was a cross sectional study with Descriptive survey design. The study was conducted among 120 children selected from high school of Bagalkot.

Setting of the study: Present study will be conducted at selected high school of Bagalkot. Tentatively Basaveshwara high school will be selected for the study.

Participants: The tentative sample size is 180 students studying in selected high school of Bagalkot. The final sample size will be 120 calculated by power analysis.

\section{Criteria for selection of sample:}

Inclusion criteria: The study includes students who are 1) able to understand, read and write English, 2) available at the time of data collection, 3) willing to participate in the study.

Exclusion criteria: The study excludes who are 1) ill at the time of data collection. 2) Unable to cooperate through the period of study. 3) Not willing to give written consent.

Sample Size estimation: sample size was estimated by adolescents of BVVS English medium high school Bagalkot is randomly selected as accessible population and high school $\left(8^{\text {th }}, 9^{\text {th }} \& 10^{\text {th }}\right)$ adolescents has been enrolled in the study as sample. 


\section{Description of data collection tool}

The data collection instrument is divided into 2 sections.

SECTION A: includes items related to socio demographic characteristics or determinants of high school students.

SECTION B: The social phobia inventory is a five point scale consists of 17-items developed by the Psychiatry and Behavioral Sciences Department at Duke University. It is effective in screening for, and measuring the severity of SAD.

Data Collection: Data collection was done by structured interview schedule is used to gather information regarding determinants or socio demographic characteristics and self-report method is used to assess the social anxiety disorder.

\section{Variables of the study:}

Dependent Variable: Determinants associated with social anxiety disorders among adolescents.

Independent Variable: Social anxiety disorder among high school students.

\section{Statistical Analysis:}

The data was analyzed using SPSS

18 statistical package. Numerical data obtained from the sample will be organized, summarized with the help of descriptive statistics like frequency, percentage distribution, arithmetic mean, standard deviation, median and correlation coefficient. Association between social anxiety disorder and its determinants among high school students using Fisher exact probability test; linear regression test and Chi square test were used to analyze association of social anxiety disorders with socio demographic variables. Ethical Consideration: Ethical clearance certificate was obtained from B.V.V.S Sajjalashree Institute of Nursing Sciences, institutional ethical committee. Written consent was obtained from each participant.

\section{RESULTS}

The study was begun with selection of 120 adolescents from BVVS English medium high school Bagalkot. All the adolescents were responded to structured questionnaire. their level of social anxiety disorders reveals that majority $83.3 \%$ had non phobic, $15.8 \%$ had mild and $0.8 \%$ had moderate, there is no extremely phobic. The analysis was carried out according to objectives of the study.

\section{SECTION A: DESCRIPTION OF SOCIO DEMOGRAPHIC CHARACTERISTICS OF ADOLESCENTS.}

\begin{tabular}{|c|c|c|c|c|}
\hline SL. NO. & Socio-demographic variables & Characters & Frequency & Percentage \\
\hline 1 & Age & $\begin{array}{l}14 \text { years } \\
15 \text { years } \\
16 \text { years }\end{array}$ & $\begin{array}{l}40 \\
40 \\
40\end{array}$ & $\begin{array}{l}33.33 \% \\
33.33 \% \\
33.33 \%\end{array}$ \\
\hline 2 & Gender & $\begin{array}{l}\text { Male } \\
\text { Female }\end{array}$ & $\begin{array}{l}65 \\
55\end{array}$ & $\begin{array}{l}54.2 \% \\
45.8 \%\end{array}$ \\
\hline 3 & Religion & $\begin{array}{l}\text { Hindu } \\
\text { Muslim } \\
\text { Christian }\end{array}$ & $\begin{array}{l}104 \\
13 \\
3 \\
\end{array}$ & $\begin{array}{l}86.7 \% \\
10.8 \% \\
2.5 \%\end{array}$ \\
\hline 4 & Year of studying & $\begin{array}{l}8^{\text {th }} \text { standard } \\
9^{\text {th }} \text { standard } \\
10^{\text {th }} \text { standard }\end{array}$ & $\begin{array}{l}40 \\
40 \\
40 \\
\end{array}$ & $\begin{array}{l}33.33 \% \\
33.33 \% \\
33.33 \% \\
\end{array}$ \\
\hline 5 & Number of siblings & $\begin{array}{l}01 \\
02 \\
03 \\
04 \\
05 \\
06\end{array}$ & $\begin{array}{l}24 \\
29 \\
33 \\
26 \\
5 \\
3\end{array}$ & $\begin{array}{l}20.0 \% \\
24.2 \% \\
27.5 \% \\
21.7 \% \\
4.2 \% \\
2.5 \%\end{array}$ \\
\hline
\end{tabular}


Nagarjun Mundinamani et.al. An Explorative study to assess the prevalence of social anxiety disorder (SAD) and its determinants among high school students of selected high school of Bagalkot.

\begin{tabular}{|c|c|c|c|c|}
\hline \multicolumn{5}{|c|}{ Table 1 Continued... } \\
\hline \multirow{14}{*}{6} & \multirow{14}{*}{ Number of members in the family } & 03 & 1 & $0.8 \%$ \\
\hline & & 04 & 1 & $0.8 \%$ \\
\hline & & 05 & 8 & $6.7 \%$ \\
\hline & & 06 & 20 & $16.7 \%$ \\
\hline & & 07 & 24 & $20.0 \%$ \\
\hline & & 08 & 25 & $20.8 \%$ \\
\hline & & 09 & 6 & $5.0 \%$ \\
\hline & & 10 & 24 & $20.0 \%$ \\
\hline & & 11 & 5 & $4.2 \%$ \\
\hline & & 12 & 4 & $3.3 \%$ \\
\hline & & 13 & 0 & \\
\hline & & 14 & 1 & $0.8 \%$ \\
\hline & & 15 & 0 & \\
\hline & & 16 & 1 & $0.8 \%$ \\
\hline \multirow{2}{*}{7} & \multirow{2}{*}{ Do you practice yoga Sana? } & Yes & 12 & $10 \%$ \\
\hline & & No & 108 & $90 \%$ \\
\hline \multirow{2}{*}{8} & \multirow{2}{*}{ Do you play sports } & Yes & 74 & $61.7 \%$ \\
\hline & & No & 46 & $38.3 \%$ \\
\hline \multirow{2}{*}{9} & \multirow{2}{*}{ You like attending social gathering } & Yes & 52 & $43.3 \%$ \\
\hline & & No & 68 & $56.7 \%$ \\
\hline \multirow{4}{*}{10} & \multirow{4}{*}{ Percentage of marks secured in previous academic year } & $91-100$ & 27 & $22.5 \%$ \\
\hline & & $81-90$ & 58 & $48.3 \%$ \\
\hline & & $71-80$ & 33 & $27.5 \%$ \\
\hline & & $61-70$ & 2 & $1.7 \%$ \\
\hline \multirow{2}{*}{11} & \multirow{2}{*}{ Do you use mobile phone } & Yes & 33 & $27.5 \%$ \\
\hline & & No & 87 & $72.5 \%$ \\
\hline \multirow{2}{*}{12} & \multirow{2}{*}{ Do you speak local language } & Yes & 120 & $100 \%$ \\
\hline & & No & 0 & 0 \\
\hline \multirow{2}{*}{13} & \multirow{2}{*}{ Are you satisfied with your academic performance? } & Yes & 120 & $100 \%$ \\
\hline & & No & 0 & 0 \\
\hline \multirow{2}{*}{14} & \multirow{2}{*}{ Are you satisfied with your facial appearance? } & Yes & 120 & $100 \%$ \\
\hline & & No & 0 & 0 \\
\hline \multirow[t]{2}{*}{15} & Have you experienced bullying & Yes & 0 & 0 \\
\hline & & no & 120 & $100 \%$ \\
\hline & Have you experienced & Yes & 0 & 0 \\
\hline 16 & battering & No & 120 & $100 \%$ \\
\hline & & 01 & 54 & $45.0 \%$ \\
\hline & & 02 & 47 & $39.2 \%$ \\
\hline 17 & Order Of Birth & 03 & 16 & $13.3 \%$ \\
\hline & & 04 & 2 & $1.7 \%$ \\
\hline & & 05 & 1 & $0.8 \%$ \\
\hline 18 & Whether Your Relation With Your Father Is Satisfactorv & Yes & 120 & $100 \%$ \\
\hline 18 & Whether Your Relation With Your Father Is Satisfactory & No & 0 & 0 \\
\hline 19 & Whether Your Relation With Your Mother Is Satisfactory & Yes & 120 & $100 \%$ \\
\hline & & No & 0 & 0 \\
\hline 20 & Do vou feel you have satisfied with vour social sunnort & Yes & 1 & $0.8 \%$ \\
\hline 20 & Do you reer you nave salisiled witn your social support & No & 119 & $99.2 \%$ \\
\hline 21 & Are you diagnosed with any diseases & Yes & 0 & 0 \\
\hline 21 & Are you uragnosed wiln any uiseases & No & 120 & $100 \%$ \\
\hline 22 & Do You Think/Believe You Have Less Number Of Friends & Yes & 0 & 0 \\
\hline & & No & 120 & $100 \%$ \\
\hline 23 & Do You Feel Difficulty Coping With Students & Yes & 0 & 0 \\
\hline & & No & 120 & $100 \%$ \\
\hline
\end{tabular}

\section{SECTION B: LEVEL OF SOCIAL ANXEITY DISORDERS AMONG ADOLESCENTS (assessment)}

Table 2: Percentage wise distribution of adolescents according to their level of social anxiety disorders, $\mathbf{N}=\mathbf{1 2 0}$

\begin{tabular}{|l|l|l|l|l|}
\hline SL. NO. & RANGE OF SCORE & Level of social anxiety disorders & Frequency & Percentage \\
\hline 1 & Less than 20 & Non phobic & 100 & $83.30 \%$ \\
\hline 2 & $21-30$ & Mild & 19 & $15.8 \%$ \\
\hline 3 & $31-40$ & Moderate & 1 & $0.8 \%$ \\
\hline 4 & $41-50$ & severe & 0 & $0 \%$ \\
\hline 5 & More than 50 & extreme & 0 & $0 \%$ \\
\hline & & TOTAL & 120 & $100 \%$ \\
\hline
\end{tabular}


Nagarjun Mundinamani et.al. An Explorative study to assess the prevalence of social anxiety disorder (SAD) and its determinants among high school students of selected high school of Bagalkot.

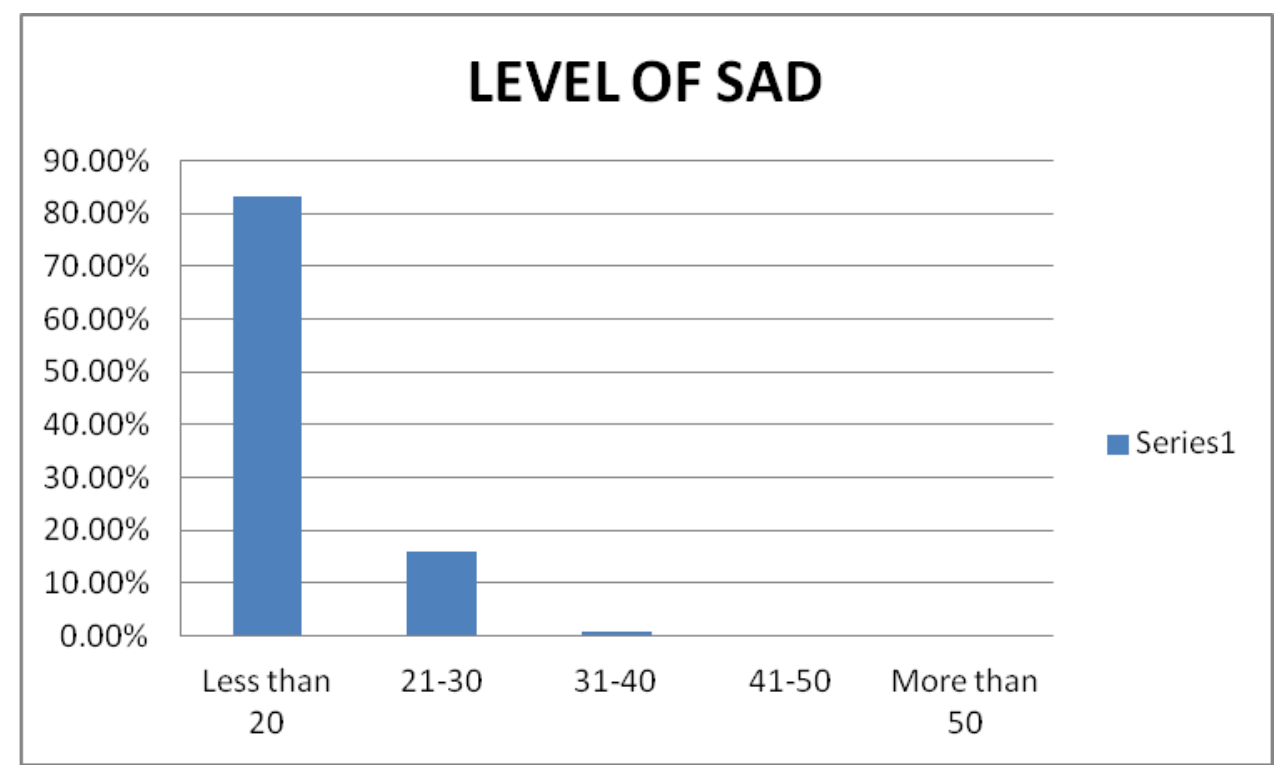

Percentage distribution of adolescents according to their level of social anxiety disorders reveals that majority $83.3 \%$ had non phobic, $15.8 \%$ had mild and $0.8 \%$ had moderate, there is no extremely phobic.

Table 3: Mean, S.D and Mean \% score for social inventory scale scores of adolescents. N=120

\begin{tabular}{|l|l|c|c|c|l|}
\hline Sl.no & SPIN Scale variables & Max score & Mean & SD & Mean \% \\
\hline 1. & Assessment prevalence of social anxiety disorders among adolescents & 34 & 17.18 & 3.69 & $52.8 \%$ \\
\hline
\end{tabular}

Results related to Mean, SD and Mean percentage of social inventory scale scores among adolescents.

The mean percentage of the social inventory scale score was $52.8 \%$ percent with mean and SD $17.18 \pm 3.69$. These findings reveal that $53 \%$ of social anxiety disorders among adolescents.
SECTION C: DESCRIPTION OF ASSOCIATION BETWEEN SOCIAL ANXIETY DISORDERS WITH THEIR SELECTED DEMOGRAPHIC VARIABLES.

H1: $_{1}$ There is significant association between social anxiety disorders and selected determinants of high school students.

\begin{tabular}{|c|c|c|c|c|c|c|c|}
\hline $\begin{array}{l}\text { Sl. } \\
\text { No }\end{array}$ & Socio demographic variable & $\begin{array}{l}\text { Chi square } \\
\text { value }\end{array}$ & $\begin{array}{l}\begin{array}{l}\text { Degree of } \\
\text { freedom }\end{array} \\
\end{array}$ & $\begin{array}{l}\mathbf{P} \\
\text { value }\end{array}$ & $\begin{array}{l}\text { Table } \\
\text { value }\end{array}$ & $\begin{array}{ll}\text { Level of } \\
\text { significance }\end{array}$ & $\begin{array}{l}\text { Significance of } \\
\text { association }\end{array}$ \\
\hline 1 & Age & 2.997 & 4 & 0.558 & 9.488 & 0.05 & NS \\
\hline 2 & Gender & 1.654 & 2 & 0.437 & 5.991 & 0.05 & NS \\
\hline 3 & Religion & 0.853 & 4 & 0.931 & 9.488 & 0.05 & NS \\
\hline 4 & location & 0.202 & 2 & 0.904 & 5.991 & 0.05 & NS \\
\hline 5 & Year of studying & 7.959 & 6 & 0.241 & 12.592 & 0.05 & NS \\
\hline 6 & Number of siblings & 11.139 & 10 & 0.347 & 18.307 & 0.05 & $\mathrm{NS}$ \\
\hline 7 & $\begin{array}{l}\text { Number of members in the } \\
\text { family }\end{array}$ & 7.116 & 10 & 0.999 & 18.307 & 0.05 & NS \\
\hline 8 & Do you practice yogasana? & 0.117 & 2 & 0.943 & 5.991 & 0.05 & NS \\
\hline 9 & Do you play sports & 5.628 & 2 & 0.060 & 5.991 & 0.05 & NS \\
\hline 10 & $\begin{array}{l}\text { You like attending social } \\
\text { gathering }\end{array}$ & 1.506 & 2 & 0.471 & 5.991 & 0.05 & NS \\
\hline 11 & $\begin{array}{l}\text { Percentage of marks secured in } \\
\text { previous academic year }\end{array}$ & 7.230 & 6 & 0.300 & 12.592 & 0.05 & NS \\
\hline 12 & Do you use mobile phone & 2.00 & 2 & 0.368 & 5.991 & 0.05 & NS \\
\hline 18 & Order Of Birth & 3.660 & 8 & 0.886 & 15.507 & 0.05 & NS \\
\hline 21 & $\begin{array}{l}\text { Do you feel you have satisfied } \\
\text { with your social support }\end{array}$ & 0.202 & 2 & 0.904 & 5.991 & 0.05 & NS \\
\hline 22 & Monthly income & 21.199 & 4 & $<0.01$ & 13.277 & 0.05 & Significant \\
\hline
\end{tabular}




\section{DISCUSSION}

The aim of the study was to assess the prevalence of social anxiety disorder [sad] and its determinants among high school students of selected high school of Bagalkot.

Similar results were found in cross sectional study conducted and estimating the prevalence of social anxiety disorders in high school students in AL BAHA area using two scales [Liebowitz scale of social anxiety] and severity scale for social anxiety and to determine risk factor which may be significant. This survey study includes 1316 students'. The sample size taken 1030 students. So the total number is 1025. The total positive sample was [21.8 $\%$ ]. There is highly significant association between Birth order and Place of residence. The result of study concluded that there is a high percentage of high school students diagnosed with social anxiety disorder (using the 2 scales) indicating the importance of the problems in Baha region for further researches behind the causes. ${ }^{7}$

Total 120 students were selected Finding depicts that their level of social anxiety disorders reveals that majority $83.3 \%$ were non phobic, $15.8 \%$ were mild and $0.8 \%$ were moderate, there is no extremely phobic. $\mathrm{H}_{1}$ : There is significant association between social anxiety disorder and selected determinants of high school students was accepted.

Finding depicts that, there is significant association found between monthly income (chi square value 11.199, p $<0.05$ ), and there is no significant association found between social anxiety disorders and selected demographic variables.

Limitations of the study: The study was confined only to exploration of Parental determinants associated with malnutrition among under five children. The study focused only on Under five children and their parents residing in rural area of Bagalkot.

\section{CONCLUSION}

Results related to Association between social phobia disorders with their socio demographic variables A significant association was found between the social anxiety disorders of adolescents and their selected socio-demographic variables like monthly income $\left(\chi^{2}=21.199 ; \mathrm{P}<0.05\right)$.

\section{ACKNOWLEDGEMENTS}

I especially wish to express deep sense of gratitude and respect to esteemed and pragmatic, Principal Dr. Deelip. S. Natekar, and co-guide Dr. Utalbasha. N. Dhandargi. Professor and HOD of Community Health nursing, I deem it a great privilege and honour to express deepest sense of gratitude to worthy, able and esteemed teacher and guide $\mathrm{Mr}$. Renukaraj Y Nagammanavar. Associate Professor of Community Health nursing, Shri B.V.V.Sangha's Sajjalashree Institute of Nursing Sciences, Bagalkot Source of Funding: Self-funding and Grant for short term research 2020-21, from Rajiv Gandhi University of Health sciences, Bengaluru, Karnataka.

\section{Conflict of Interest: None}

\section{Source of Funding: None}

\section{Ethical Approval: Approved}

\section{REFERENCES}

1. Gregory M.Rose, Prasanna Tadi, NCBI, U.S National library of medicine, about SAD, July 7, 2021, (2-3).

2. National institute mental health information (official website).nimh.nih.gov.com (website link).

3. National Institute of Mental health (NIMH) U.S Department of health and human services (official website). Google Scholar.

4. Elenator Leigh and David.M, CLARK, clinical child and family psychology review published in 2018.

5. National center for Biotechnology, U.S national library of medicine (official website) .ncbi.nlm.gov.com(website link). 
Nagarjun Mundinamani et.al. An Explorative study to assess the prevalence of social anxiety disorder (SAD) and its determinants among high school students of selected high school of Bagalkot.

6. Anxiety and depression association of America $\{$ ADAA $\}$ (official website) adaa.orglunderstanding/anxiety/social anxiety disorder(website link)

7. National Institute of Mental health U.S Department of health and human services (official website). Google ScholarHatice K, Gündüz Y. Relationship between Psychological Well-Being and Smartphone Addiction. International Journal of Higher How to cite this article: Nagarjun Mundinamani, Renukaraj Nagammanavar, Deelip S Natekar et.al. An explorative study to assess the prevalence of social anxiety disorder (SAD) and its determinants among high school students of selected high school of Bagalkot. Int $J$ Health Sci Res. 2022; 12(1):117-123. DOI: https://doi. org/10.52403/ijhsr.20220117 